\title{
Research on Time Bank's Mutual-support Old-aged Care Mode Based on Blockchain Technology
}

\author{
Xiaoxiang Zhang ${ }^{1, *}$, Qianfan $\mathrm{Xu}^{1}$ \\ ${ }^{1}$ School of Management of Hubei University of Traditional Chinese Medicine, Wuhan City, Hubei Province, China
}

\begin{abstract}
With the development trend of aging and low fertility in China, disability and dementia increase year by year in the elderly population. The demand of long-term life care service for the elderly with disability and dementia brings great challenges to the service supply and funds of the traditional endowment insurance model. However, with the application of blockchain technology, the Time Bank's mutual-support old-aged care mode can better solve the above problems. First, the author uses SWOT analysis to comprehensively analyze the advantages, difficulties, opportunities and challenges of the Time Bank's Mutual-support for the Aged mode in China, then the blockchain technology is applied to this mode, finally the corresponding optimization scheme and suggestions are put forward.
\end{abstract}

\section{Introduction}

With the increasingly severe ageing of our population, some social problems have gradually come to the fore. These social problems not only refer to the decrease of labor force, the increase of financial pressure on pension and medical costs. More importantly, with the social trends of aging and low fertility, the most intractable problem is that the demand for long-term life care services for the elderly with disability and dementia cannot be met with each passing year. To better implement the policy of overcoming the population aging, it is necessary to find a path suitable for China's national conditions to solve the problem of care service supply for the elderly with disability and dementia.

Different countries in the world have put forward various solutions to solve the problem of care service for the elderly with disability and dementia, in which "Time Bank" raised by American Edgar Kahn in the 1990s has great advantages. Time Bank, as a mutual aid mode, can effectively solve many old-age care problems caused by aging. However, Time Bank is still in a slow progress in China. Its own shortcomings shall be the main reason why Time Bank old-age care mode has not been popular.

\section{Advantages of Time Bank}

\subsection{Paid Incentive Mechanism}

Time Bank works in a way that help the elderly in need in exchange for time of being served when they are aged. This mutual-support model is often mistaken for voluntary act. There is an essential difference between Time Bank mechanism and volunteer service, because all the services in Time Bank are paid for the exchange of time. People with the ability to serve the elderly in need can obtain care when they are aged in the future. Through this paid incentive mechanism, the mutual service under the Time Bank mode not only conforms to our traditional idea of "receiving rewards for one's virtuous deeds", but also meets people's demand for elderly care services ${ }^{[1]}$.

Meanwhile, with the operation of the intangible time assets, Time Bank has the property of saving. Time Bank, literally refers to bank. Therefore, it must have the same properties of a bank, including saving money. The saving property of Time Bank brings advantages that the service time can be deposited at any time and with high flexibility to this old-age care mode. Moreover, the fact that the accounts of savings are clear also gives participants greater reassurance. If Time Bank is widely promoted, it will be very convenient for people to deposit and withdraw money in different regions around the world.

Therefore, the incentives of paying time currency will greatly improve the service quality, enhance the

* Corresponding author: 422616556@qq.com 
willingness of participants, and make them feel more at ease. In the long run, maintaining such a positive state is also conducive to ensuring the long-term implementation of the old-aged care mode of Time Bank.

\subsection{Alleviate the Shortage of Elderly Care Personnel}

The aging of the population will lead to a shortage of professional medical staff, but anyone who is in a healthy condition has certain ability to take care of the elderly. Although they may not be as good as professional medical staff, they can meet the basic needs of the most elderly people after receiving relevant pre-job training. Under the Time Bank system, the elderly separately releases their demands for various services, so the service providers do not need to take care of the elderly for a long time. They can choose the projects they are competent at depending on the circumstances. In this way, the problem of insufficient old-age medical personnel can be well solved.

However, the services that the Time Bank provides and requires should not involve professional medical care which should be undertaken by medical insurance or longterm care services. The services provided by the Time Bank are mainly concerned with life care of the elderly.

\subsection{Avoid Inflation}

As a very common way of old-aged care, saving still has some defects, one of which is the difficulty of avoiding inflation. It is hard to guarantee that savings still have the same value when they are exchanged in the future. Therefore, although savings are safe and sound in the short term, there is a certain depreciation risk in the long term. The Time Bank avoids inflation because it stores time, not money. Although recorded in the form of time currency, the essence of its transactions is time. Time has a better store of value than money. It is perfectly fair to trade one unit of time for another, regardless of its value.

\section{The Dilemma of Time Bank Development}

\subsection{It Is Difficult to Unify the Deposit and Exchange Rules}

Only if the store and conversion rules are professional, can the long-term care service become sustainable. However, nowadays it is difficult to scientifically and reasonably convert the service into standard hours stipulated by the Time Bank according to service intensity and difficulty ${ }^{[2]}$. With the development of productivity, various new services will emerge in the future. How to exchange these new services is an issue that needs professional consideration.

The scope of mutual-support in this mode must have boundary. At present, the needs of the participants involve from medical care to chat. It is a very serious problem which has affected the supply of services and the formulation of exchange rules. Professional services can be merely provided and it is also difficult to determine how much time should be appropriately paid for easy and simple services. Therefore, these two types of service should be removed from mutual-support service. It is the primary challenge for Time Bank to formulate an appropriate scope of mutual-support projects.

\subsection{Scope of Service Has Not Been Improved}

Now the Time Bank's services are limited to a small scope, so the participants will not be able to withdraw time to get services beyond this scope. Moreover, due to different standards of Time Banks or mutual-support institutions, the standard of store and exchange will also be inconsistent with that of the banks in the original residence. It is not easy to expand the implementation scope of Time Bank, which needs the macro intervention of the government. Meanwhile, simplifying the Time Bank transfer procedures when moving is required.

\subsection{Complex Determination of Operating Expenses}

To undertake the store and confirmation of a service item, Time Bank should charge a certain amount of service fees to maintain its own management and operation. However, if the handling fee of each transaction is too high, it will cause economic burden to users who need a large number of services, which may lead to the low utilization rate of Time Bank, finally it is hard for Time Bank to continue operating. But low handling fee makes Time Bank cannot make ends meet and they can only rely on the governmental financial support. Therefore, the determination of service fee also needs careful calculation and study.

\subsection{Children Cannot Be Completely Replaced}

Since all the services provided by the Time Bank are taskoriented, they can only provide intimate services to the elderly within a limited period of time to deliver warmth. After the work, the service provider may not contact with the elderly. On the other hand, the services the elderly receive may be different each time. Such services can only meet the daily needs of the elderly, but it is difficult to meet the spiritual demands. Therefore, the Time Bank mutual-support mode cannot completely replace the role of children. 


\section{Opportunities for Implementing Time Bank's Mutual-support Old-aged Care Mode}

\subsection{Alleviate Financial Burden under the Epidemic Situation}

It is particularly important to realize that the implementation of the mode of Time Bank old-aged care will effectively alleviate the national financial burden, especially under the background of the pandemic. The proportion of the elderly aged over 60 in China has reached $15.5 \%$ now, $17.7 \%$ in 2020 and $31.5 \%$ in 2050 , respectively. In this trend, the labor force is insufficient while the elderly population is overwhelming, which greatly increases the financial burden. Taking the basic endowment insurance for urban enterprise employees as an example, after excluding financial subsidies, the income and expenditure of endowment insurance fund in 2015 face the deficit of 302.487 billion yuan, which was significantly larger than that of RMB 156.3 billion in 2014, while in 2012, this indicator was positive. That is to say, the overall operation of the pension insurance system in China is stable currently, mostly because the government is undertaking the financial responsibility of "pocket", and constantly provides financial subsidies for the pension insurance system. Through Time Bank, it can reduce the financial and economic subsidies for the elderly ${ }^{[3]}$. The part of financial expenditure originally used to pay for endowment insurance or elderly health insurance will be replaced by mutual-support among Time Bank participants.

This kind of substitution has two advantages, which is a benign alternative. First, the mutual-support old-aged care mode of Time Banks reduces the expenditure of finance, because the elderly solves their needs by exchanging services in Time Bank, such as some life needs. Such needs should have been funded by pension or nursing insurance, but can be met by time exchanging currency, which can relieve the financial pressure of the government. Second, Time Bank has better effect than pension. Many old people are reluctant to spend money for themselves, even if they get pension. If their children are in need, they will have no hesitation to lend them. In this way, pension has no practical positive effect on the elderly, but Time Bank is different. In Time Bank, people can only exchange time with time, so there is no problem above. Moreover, participants in the Time Bank old-aged care mode will serve the elderly in need heartily in order to get good services from others when they are old, so that the quality of the pension is guaranteed. Therefore, Time Bank has obvious advantages in reducing financial expenditure and improving the elderly's pension treatment.

\subsection{Solve the Life Care Problems of the Elderly with Disability and Dementia}

With the increasingly serious aging of the population, the number of the elderly with disability and dementia is also increasing. Today, there are about 50 million elderly people with disability and dementia in China. These elderly people have more difficulties in daily life than others, so they need long-term care which is often not affordable for their children. The mutual-support mechanism based on the Time Bank can replace caregivers such as children to a certain extent and help these old people solve difficulties in their daily lives.

Table 1. Number of the Elderly with Disability and Dementia

\begin{tabular}{|c|c|c|}
\hline \multirow{2}{*}{ Year } & \multicolumn{2}{|c|}{$\begin{array}{c}\text { Number of the Elderly with Disability and } \\
\text { Dementia }\end{array}$} \\
\cline { 2 - 3 } & Percentage & Number \\
\hline 2010 & $19.00 \%$ & $33,000,000$ \\
\hline 2015 & $18.30 \%$ & $40,630,000$ \\
\hline 2020 & $17.00 \%$ & $42,500,000$ \\
\hline 2030 & $17.00 \%$ & $62,900,000$ \\
\hline 2050 & $20.00 \%$ & $96,000,000$ \\
\hline
\end{tabular}

\subsection{Promote Social Civilization Construction}

The implementation of Time Bank is undoubtedly conducive to social civilization and harmony. Although the Time Bank old-aged care mode is non-voluntary act, the service spirit is always carried out. With paid incentives, service providers are more willing to devote their time to serve others. Such a positive circulation system has a positive promotion to people's morality and social atmosphere.

\section{Challenges Facing the Implementation of Time Bank}

\subsection{Trust Issues Have Not Been Resolved}

Whether time currency can be successfully withdrawn or not in the future is the main reason why people distrust Time Bank at present. There are several major reasons for concerns about time currency conversion. First, the records in the bank are continuously increasing over the decades while the bank has to keep all the data for decades due to the long time. Not only retrieving such a huge database in the future is complicated, but even data error or retrieving failure may also appear. Second, bank staff may also face the issue of retirement, and the job handover easily goes wrong. If there is something wrong in the future, it's very difficult to find the original person in charge to fix the problem. Third, some natural disasters are unavoidable. The occurrence of various accidents eventually leads to the loss of data. Fourth, there may be manipulation of data. If someone has the ability to manipulate data for personal interest, it is certainly unfair to others. Fifth, the uncertain long-term existence of the Time Bank is also a cause for the concern. Relevant 
policies have not yet been put in place, not to mention if the policies can last long. However, once the Time Bank is unable to continue its business due to some reasons, the participants cannot withdraw the time paid previously. For these reasons, the credibility of Time Bank is still facing great challenges.

\subsection{Contradictions Exist Between Paid services and Secularization}

This contradiction mainly exists in the mutual assistance between acquaintances. The so-called secularization refers to the mutual influences on people's behaviors exerted by a certain relationship. In the operation system of Time Bank, the service spirit must be carried out all the time and the paid incentive mechanism is also established for high quality services provided by participants. There are rules that must be followed as to what intensity of service should be remunerated, or problems of unfairness and service inertia arise. Under the influence of secularization, if acquaintances serve each other, it will be a very practical problem whether service providers will be embarrassed to ask for remuneration corresponding to the service level. If service providers serve acquaintances with a high-quality service at a low price, they will not get fair remuneration for their own behavior and others who require service will feel unfair, resulting in the phenomenon of mutual service exclusive for acquaintances. If service providers follow the exchange rules when providing services for acquaintances, conflicts with acquaintances will emerge because of secularization. Paid services tend to make the service providers interestoriented, which is also in contradiction with secularization.

\subsection{Population Ratio Still Needs to Be Improved}

The existence of Time Bank is to alleviate the old-aged care problems caused by population aging, but it is not advisable to merely rely on Time Bank while ignoring the continuing severity of aging. As the aging population increases, there will be an imbalance between supply and demand. More old people mean more demands, while less labors mean less supply. The situation will get worse as aging continues. Therefore, when using the Time Bank to alleviate the old-aged care problem, improving the population ratio should be the government's priority.

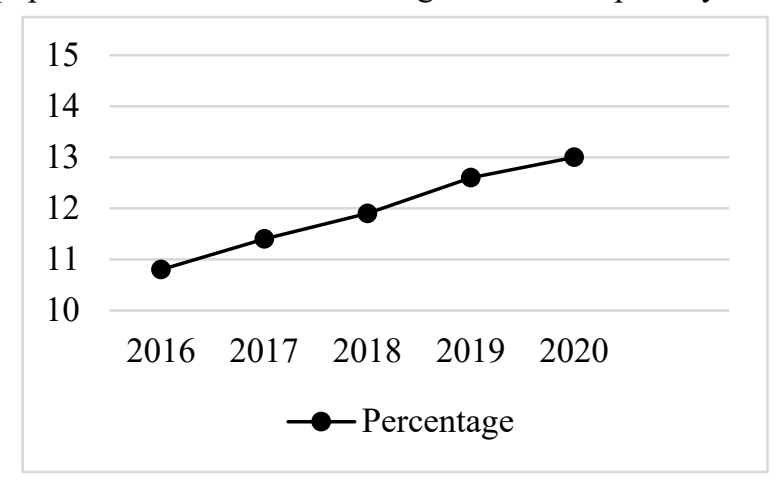

Fig. 1. Proportion of People over 65 Years Old

\section{Blockchain Technology Boosts the Launch of Time Bank Old-aged Care}

\subsection{The Decentration of Blockchain Overcomes Data Isolation}

The most disruptive thing about blockchain as an emerging technology is that it weakens the center through distributed ledger. In the case of a clear center, the problem of "data islands" is highlighted. Data is partitioned and monopolized to form data islands isolated from each other. Data is of great significance for all enterprises in the current market economy. Only by mastering big data can they master the discourse power of the market. Therefore, in the process of data competition, users and enterprises compete against each other, and enterprises gain their benefits at the expense of users' losses. Separated interests promote the formation of "data islands" between each other. ${ }^{[4]}$ And in the traditional Internet situation, we can only realize the dissemination of data, rather than the definition of data property rights. This problem of data right confirmation leads to the possession of a large amount of data by many third-party guaranteed enterprises for free, which damages the interests of citizens in the case of forming data islands.

Blockchain uses the power of a distributed ledger to connect blocks and allow data to flow so that most data are no longer in the hands of the minority. Blockchain establishes data property rights by overcoming "data islands". This has a great positive effect on the implementation of the Time Bank old-aged care mode. The trust problems caused by some human factors in the promotion of Time Bank, such as the manipulation of data for private interests, will be well solved. The elimination of "data islands" makes it almost impossible to modify records on a chain without authorization. In addition, the weakened center will no longer be interfered by powerful forces, making Time Bank system based on blockchain technology completely open and transparent to the public, which not only guarantees the security of the data on the chain, but also guarantees that every participant can be treated fairly.

\subsection{Build a One-stop Smart Contract}

Another innovation of blockchain is to build a one-stop smart contract which is a set of commitments defined in digital form. The commitments control the digital assets, contains the rights and obligations of contract participants and are automatically executed by a computer. ${ }^{[5]}$ The biggest advantage of such a smart contract lies in its high execution, low cost and automatic execution. With the features of center-weakening, immutability and the open and transparent process, blockchain technology gives full play to the advantages of smart contracts. The data stored on the chain can be integrated according to its characteristics. The one-stop data is conducive to providing the data to the smart contract for judgment and execution, so that the work on the whole chain becomes 
fast and accurate.

Building a one-stop smart contract is of great significance for Time Bank. First, the automatic execution and immutability of contracts made Time Bank a rulesbased system that was not subject to the decisions by the few. Secondly, the smart contract exists in the blockchain. As the blockchain technology can store a huge amount of data that cannot be deleted so that the data retrieval can be guaranteed, the participants of the Time Bank need not worry that the work they have done cannot be verified. It not only solves the problem of time storage and retrieval, but also can write the storage and conversion rules as well as service contents into the smart contract. This ensures that the rules are long-standing and will not be tampered with. The change of rules is up to the participants in case in the future. Finally, the contradiction between paid service and secularization can be limited. The content of the contract is automatically executed and the one-stop process is open and transparent. All the behaviors of both the service provider and the service object will be recorded, and how much is paid is clear on the chain. Once there is a problem, it is a violation of the contract, then the behavior is invalid or will be punished. Here the blockchain technology is a good example of its regulatory mechanism, which prevents violations of smart contracts through the joint supervision of all participants.

\subsection{On-chain Governance Improves Efficiency}

On-chain governance is also one of the advantages of blockchain technology. Compared with off-chain governance, it has such advantages as high efficiency, transparency and easy supervision. First of all, the efficiency of on-chain governance is reflected in the fact that it can well complete the instructions that need to be fulfilled through a series of smart contracts. In addition, blockchain can cover a large area so that it can reduce a lot of unnecessary waste of resources when managing on the chain. Second, on-chain governance will also be transparent based on the feature of open and transparent mechanism of blockchain technology. On the one hand, this strengthens public credibility; on the other hand, it also curbs bad behaviors in the implementation of the directives, thus speeds up the efficiency of governance. Third, it is easy to regulate. On-chain governance weakens central governance, where all participants have the right to regulate. The automated determination of smart contracts could also make errors more visible to the public. Therefore, blockchain's on-chain governance is an important innovation in improving the administrative efficiency.

Through on-chain governance, the geographical scope of Time Bank services can be expanded. In the off-chain governance, the instruction is slow, and the area space is large, so it can only be managed from a top-level center down to the low-level center. This greatly limits the service scale of Time Bank, which results in a consequence that the service record becomes a blank check once the participant moves. On-chain governance, through online instructions, carries out the overall regulation of all institutions existing on the chain, and solves the management problem of establishing Time Banks on a large scale. At the same time, it can also realize the trans-regional storage and conversion of services by recording all the data of different institutions in the blockchain.

\subsection{Reduce Marginal Transaction Costs}

The fourth advantage of blockchain is that it largely reduces marginal transaction costs. The records of all transactions in the blockchain are searchable, and the blockchain can be used on a large scale, so the transaction price does not vary too much in the transaction. And there is no middleman on the chain trade to make a profit, which also greatly reduced the cost of marginal trading. Meanwhile, the problem of service fees in Time Bank will be easily solved. High agency service charge due to the information asymmetry can be avoidable, and the operation costs of the bank system can be reduced to the maximum extent through blockchain. Therefore, Time Bank can truly be a system established for old-age service, rather than for profit.

To sum up, blockchain technology has a major advantage in addressing the challenges in Time Bank oldaged care system. Therefore, during the pilot implementation of Time Bank, blockchain technology can be taken into consideration to solve some of the problems encountered.

Due to the existing problem of aging population, Time Bank will become a trend in the future with its many advantages to deal with the old-aged care problem. The challenges in the implementation of Time Bank are also factors that cannot be ignored affecting its implementation and popularization. As mentioned above, how to better implement Time Bank actually refers to how to overcome the challenges of Time Bank. Blockchain can overcome many challenges of Time Bank, so blockchain can be regarded as a golden key to solve the problems of Time Bank. However, as an emerging technology, blockchain is still in its infancy, so it will inevitably have its own challenges. Whether there will be new technologies to overcome the challenges of blockchain in the future remains to be further studied. However, with regard to the current pilot situation, blockchain can help the Time Bank with better operation. Therefore, we believe that it is feasible and advantageous to apply blockchain technology to Time Bank old-aged care.

Although blockchain technology can solve the challenges of Time Bank old-aged care mode, social challenges including the disproportion of population, and the irreplaceability of children cannot be solved by blockchain. How to overcome these difficulties will be the future research direction of the old-aged care industry.

\section{Conclusion}

All in all, with the development of blockchain and the wide application of "Internet Plus" technology in China have laid a technical foundation for implementing the mutual assistance mode of Time Bank. As a new 
technology, blockchain technology has many advantages to foster the development of the Time Bank old-age care mode. It will bring a creative development for the Time Bank industry if the two can be organically combined. This paper study the sustainable development of Time Bank old-age care mode from several aspects: the advantages and challenges of Time Bank, the advantages of blockchain and how to use blockchain technology to overcome the disadvantages of Time Bank.

\section{References}

1. Yuan Zhigang. (2019) Time Bank: the possibility and feasibility of the new mutual pension $[\mathrm{J}]$. Exploration and Contention, No.358, 6-38+199.

2. Wang Dan. (2015) Research on the Sustainability of Financial Affordability of Pension System Insurance in China [C]. Dongbei University of Finance and Economics.

3. Xia Xinping. (2014) Time Bank: a new mode of urban community pension service $[\mathrm{J}]$. Chinese Journal of Gerontology ,v34, 295-297.

4. Zhou Maojun. (2018) Empowerment and Reconstruction: Blockchain Technology's Cracking of Data Isles [J]. Journalism \& Communication Review,v.71;No. 358,59-68.

5. Zhao Jinxu; Meng Tianguang. (2019) Technology Empowerment: How Blockchain Reshaping Governance Structure and Model [J]. Contemporary World and Socialism, No.139,189-196. 